\title{
Backward masking by pattern mask: Effect of adaptation and target energy
}

\author{
DEAN G. PURCELL* \\ University of Arkansas, Fayetteville, Ark. 72701 \\ and \\ ALAN L. STEWART
New York University, New' York, N.Y. 10003
}

Correct report of the capital target letters " $A$ " and " $T$ " was determined with a pattern mask for conditions of high and low target energy under light and dark adaptation. The level of target energy interacted with the adaptation state. With low energy targets, target report was highest under dark adaptation. With high energy targets, target report was highest under light adaptation. These findings were incompatible with Scharf \& Fuld's (1972) hypothesis of the influence of adaptation state on masking by a visual pattern.

Under conditions of dark-adapted metacontrast, an increase in target luminance or duration may result in a decrease in target detection (Purcell, Stewart, \& Dember, 1969; Purcell \& Stewart, 1969). The present study was designed to determine if an increase in the luminance or duration of a target letter would decrease target recognition under backward masking by a pattern mask. Comparisons were also made between masking under conditions of light and dark adaptation.

\section{METHOD \\ Observers \\ Four well-trained paid Os served in this experiment.}

\section{Apparatus and Procedure}

The target stimulus set consisted of the white-on-black capital letters " $T$ " and "A." Each letter was about 29 min high by $24 \mathrm{~min}$ wide. The strip width of the letters was about 5 min. Target luminance levels of $20 \mathrm{~mL}$ and $60 \mathrm{~mL}$ were tested at a short $(10-\mathrm{msec})$ and a long target duration. The long target duration was different for each $\mathrm{O}$, but was equal to the interval $(-\Delta t)$ between the onset of the target and the onset of the mask. The pattern mask was made up of overlapping row s and columns of the black-on-white capital letters "N" and "O." The angular subtense and strip width of each individual letter was the same as a target letter. The size of the pattern was 153 min high by 180 min wide. The white portions of the mask had a luminance of $20 \mathrm{~mL}$. The exposure duration of the mask was $150 \mathrm{mnsec}$.

The target letter was alway's exposed at the center of the presentation field. Os fixated a 1 -min red dot 100 min to the left of where the target was exposed. The fixation field was either dark or light prior to the onset of the mask. Under the light-adapted condition, the luminance of the fixation field was $5 \mathrm{~mL}$. The lighted field was exposed for $1 \mathrm{sec}$ and terminated at the onset of the target field.

The interval $(-\Delta t)$ between target onset and mask onset was fixed for each $\mathrm{O}$ so as to yield between $60 \%$ and 80 \% correct target report under the light-adapted long duration. 20-mL target condition. During the experimental trials, all conditions of target

*Requests for reprints should be sent to Dean G. Purcell, Department of Psychology, University of Arkansas. Fayetteville, Ark. 72701 . luminance, duration, and adaptation were completely crossed for all Os. Fifty trials were run under each condition in random blocks of 10 trials each. The O's task was to make a forced-choice decision as to which target letter, " $A$ " or " $T$," had been presented. The order of presentation of the targets was determined randomly. Os were dark adapted for $10 \mathrm{~min}$ before data collection. The intertrial interval was $10 \mathrm{sec}$. All observations were binocular. The target, mask, and adaptation fields were square, $180 \mathrm{~min}$ on a side. The Os initiated each trial at a ready signal from E. A Scientific Prototype tachistoscope was used to present all stimuli.

\section{RESULTS}

See Table 1 for the mean percent correct target report obtained under each condition. The effect of target luminance on target report was not statistically significant. The effect of target duration on target report was statistically significant, $F(1,3)=31.35, \mathrm{p}<.025$. These results are qualified by the finding that target luminance and target duration interacted, giving an $\mathrm{F}(1,3)=15.90, \mathrm{p}<.05$. There was no statistically significant effect of adaptation, but adaptation did interact with target duration, $F(1,3)=29.66, p<.025$, and target luminance, $F(1,3)=74.24, p<.005$. The three-way interaction of target luminance, target duration, and adaptation was also statistically significant, $F(1,3)=55.57, \mathrm{p}<.01$.

\section{DISCUSSION}

These results indicate that, under dark adaptation, increasing the target luminance or duration will decrease target recognition. This finding is consistent with the findings of Purcell, Stewart \& Dember (1969) and Purcell \& Stewart (1969). These results also indicate that under light adaptation, increasing the target luminance or duration will increase target recognition. This indicates that the findings of Purcell et al and Purcell \& Stewart (1969) will not generalize to conditions of light adaptation.

This study also demonstrated, at the high levels of target luminance and duration, that target report under light adaptation is better than target report under dark adaptation. Scharf \& Fuld (1972) have formulated a specific hypothesis to deal with findings which are similar to those found in the present experiment. However, certain aspects of the present data are inconsistent with Scharf and Fuld's hypothesis. Scharf and Fuld argued that under dark adaptation the first few milliseconds of

Table 1

Mean Percent Correct Target Report for the On and Off Target Presentation Conditions at 20 and $60 \mathrm{~mL}$ Under Light and Dark Adaptation

\begin{tabular}{crr}
\hline & \multicolumn{2}{c}{ Target Luminance $(\mathrm{mL})$} \\
\cline { 2 - 3 } & 20 & 60 \\
\hline Dark Adaptation & & \\
On Condition & 97.50 & 68.00 \\
Off Condition & 99.50 & 83.00 \\
Light Adaptation & & \\
On Condition & 81.50 & 100.00 \\
Off Condition & 49.00 & 97.00 \\
\hline
\end{tabular}


target exposure served only to adapt the visual system, and no target information could be gained while the adaptation was taking place. On the other hand. under light adaptation target information could be acquired from the first few milliseconds of the target exposure because adaptation had already taken place. Thus, target report should be higher under light adaptation because the target was potentially available to the $O$ for a longer period of time before the onset of the mask. The present data pose two problems for Scharf and Fuld's position.

The first problem concerns the finding that under dark adaptation the $60-\mathrm{mL}$ short duration target yields higher target report than the $60-\mathrm{mL}$ long duration target. This indicates that processing of the target is occurring in the first few milliseconds of the target exposure under conditions of dark adaptation. The second problem concerns the finding that under light adaptation, correct report of $20-\mathrm{mL}$ targets fell below that found for dark-adapted $20-\mathrm{mL}$ targets. Light adaptation also reduced report of the short duration $20-\mathrm{mL}$ target more than it did report of the longer duration $20-\mathrm{mL}$ target. These findings indicate that under light adaptation the first few milliseconds of target exposure may not be available to the $O$, and may not be masked by the adaptation field.

The finding that, under dark adaptation, increases in target energy reduced target report supports the hypothesis that target report is best when the target energy level is close to a low adaptation level. This does not seem to be true under light adaptation. since target report was lowest for those target energy conditions which were closest to the adaptation level.

\section{REFERENCES}

Purcell, D. G., \& Stewart, A. L. Facilitation of visual backward masking by increasing target duration: A methodological extension. Psychonomic Science, 1969, 17. 360-361.

Purcell, D. G., Stewart, A. L., \& Dember, W. N. Backward masking: Facilitation through increased target-field luminance and duration. Psychonomic Science, 1969, 15, 87-88.

Scharf, B., \& Fuld, K. Reduction of visual masking by a priming flash. Journal of Experimental Psychology, 1972, 94, 116-118.

(Received for publication November 5, 1973.) 